\title{
Jorge López-Villarreal ${ }^{1}$, Virginia C. Castro-Peña ${ }^{1}$, Francisco Solis-Pomar ${ }^{*}$,
} Claudio D. Gutierrez-Lazos ${ }^{1}$, Manuel F. Meléndrez ${ }^{2}$, Eduardo MartínezGuerra $^{3}$, Eduardo Pérez-Tijerina ${ }^{1}$, Abel Fundora ${ }^{4}$

${ }^{1}$ Faculty of Physical-Mathematical Sciences, Universidad Autónoma de Nuevo León, San Nicolas de los Garza, Nuevo León 66451, México.

${ }^{2}$ Hybrid Materials Laboratory (HML), Department of Materials, Engineering (DIMAT), Faculty of Engineering, University of Concepcion, 270 Edmundo Larenas, Casilla 160-C, 4070409 Concepcion, Chile.

${ }^{3}$ Advanced Materials Research Center S.C., Unidad Monterrey-PIIT, Apodaca, Nuevo León 66600, México.

${ }^{4}$ Institute of Materials Science and Technology (IMRE), Universidad de La Habana, Zapata y G, Vedado, CP 10400

La Habana, Cuba.

Corresponding author: francisco.solispm@uanl.edu.mx

\section{Graphical abstract}
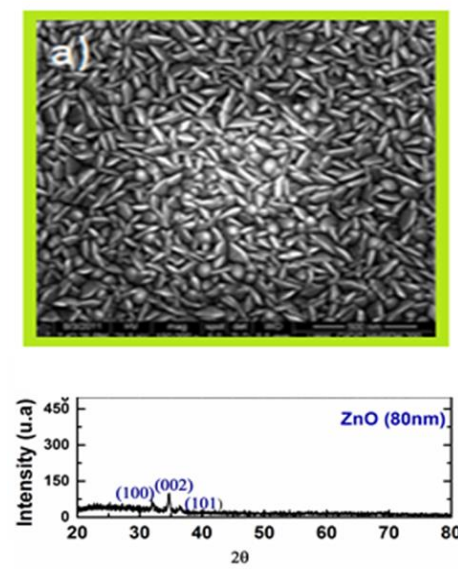

Zn seeds

(Temperature 1)
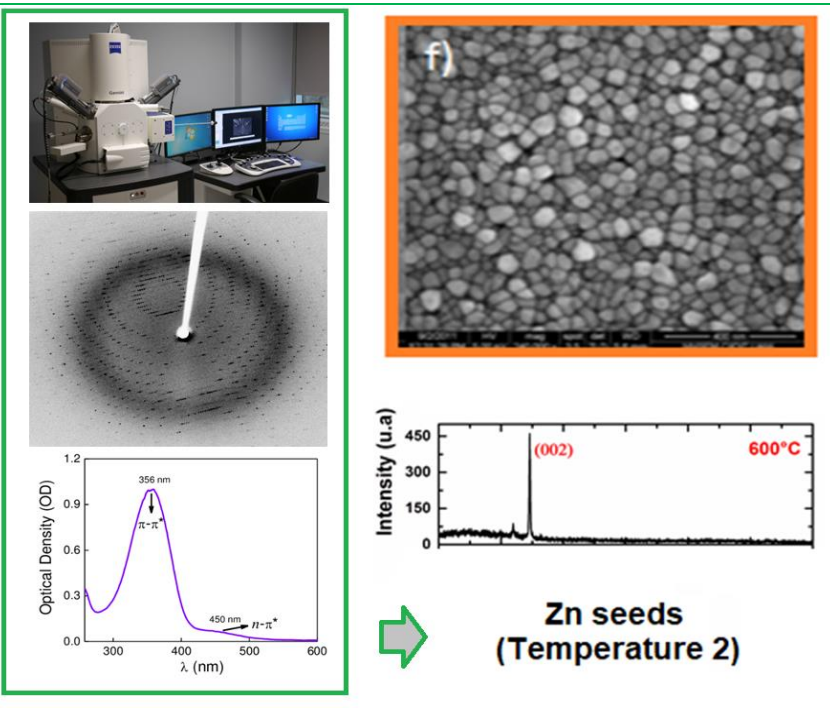

Zn seeds

(Temperature 2)

\section{Thermal treatment of $\mathrm{ZnO}$ seed layer into Atomic layer deposition to improve crystal quality of $\mathrm{ZnO}$ nanorod arrays}

\footnotetext{
Abstract

Vertically arrayed $\mathrm{ZnO}$ nanorods were synthesized by a hydrothermal method on homoseed layers deposited using atomic layer deposition (ALD) and heat-treated at various temperatures ranging from 200 to $600{ }^{\circ} \mathrm{C}$ in air. The effect of the annealing temperatures on nanorod formation was investigated. With increasing temperature, the microstructure of the $\mathrm{ZnO}$ seed layers changed from nanocrystals to coarse polycrystals with a preferred orientation, which led to an increase in the length and diameter of the solvothermally
}

Keywords Atomic layer deposition Znप Nanorads Thermal treatments 
grown nanorods. The effects of the post-heated $\mathrm{ZnO}$ seed layers on the structural and optical properties of the $\mathrm{ZnO}$ nanostructures were investigated by scanning electron microscopy (SEM), x-ray diffraction (XRD) spectroscopy and UV-Vis spectroscopy. The average grain sizes in the $\mathrm{ZnO}$ seed layers increased with increasing post-heating temperature. The $\mathrm{ZnO}$ seed layers post-heated in the range $200-600{ }^{\circ} \mathrm{C}$ affected the residual stress, lattice distortion in the $\mathrm{ZnO}$ nanostructures and the intensity, positions, and full widths at half maximum of $2 \theta$ in the XRD for the $\mathrm{ZnO}$ nanostructures. In this work, it is demonstrated that the heat-treatment temperature of $\mathrm{ZnO}$ seed layer plays an important role in the crystallinity and alignment of the $\mathrm{ZnO}$ nanorods.

\section{Tratamiento térmico de la capa de semillas ZnO en deposición de capa atómica para mejorar la calidad de los cristales de las matrices de nanocables}

\begin{abstract}
Resumen
Los nanorods de $\mathrm{ZnO}$ agrupados verticalmente se sintetizaron mediante un método hidrotermal sobre capas de homo-semillas depositadas usando Deposición de Capa Atómica (ALD) y tratadas térmicamente a diversas temperaturas que varían de 200 a 600 ${ }^{\circ} \mathrm{C}$ en aire. Se investigó el efecto de las temperaturas de recocido en la formación de nanorod. Con el aumento de la temperatura, la microestructura de las capas de semillas de $\mathrm{ZnO}$ cambió de nanocristales a policristales gruesos con una orientación preferida, lo que condujo a un aumento en la longitud y el diámetro de los nanoalimentos cultivados por vía solar. Los efectos de las capas de semillas de $\mathrm{ZnO}$ precalentadas sobre las propiedades estructurales y ópticas de las nanoestructuras de $\mathrm{ZnO}$ se investigaron mediante microscopía electrónica de barrido (SEM), espectroscopía de difracción de rayos X (XRD) y espectroscopía UV-Vis. Los tamaños promedio de grano en las capas de semillas de $\mathrm{ZnO}$ aumentaron con el aumento de la temperatura de postcalentamiento. Las capas de semillas de $\mathrm{ZnO}$ postcalentadas en el rango de 200 - $600{ }^{\circ} \mathrm{C}$ afectaron el estrés residual, la distorsión de la red en las nanoestructuras de $\mathrm{ZnO}$ y la intensidad, las posiciones y los anchos completos a la mitad como máximo de $2 \theta$ en la XRD para las nanoestructuras de $\mathrm{ZnO}$. En este trabajo, se demuestra que la temperatura de tratamiento térmico de la capa de semilla de $\mathrm{ZnO}$ juega un papel importante en la cristalinidad y la alineación de los nanorods de $\mathrm{ZnO}$.
\end{abstract}

\author{
Palabras clave \\ Deposición de capa \\ atómica \\ Nanorads de ZnD \\ Tratamienta térmico
}

Recived: $18-10-2018$

Accepted: 22-04-2019

Publishing date: 15 - May - 2019

Revision Code: 2018I|[I8-MSPL [Pag. IO8 - I17]

Corresponding author:

francisco.solispm国uanl.edu.mx 


\title{
Thermal treatment of $\mathrm{ZnO}$ seed layer into Atomic layer deposition to improve crystal quality of $\mathrm{ZnO}$ nanorod arrays
}

\author{
Jorge López-Villarreal ${ }^{1}$, Virginia C. Castro-Peña ${ }^{1}$, Francisco Solis-Pomar ${ }^{1 *}$, \\ Claudio D. Gutierrez-Lazos ${ }^{1}$, Manuel F. Meléndrez ${ }^{2}$, Eduardo Martínez- \\ Guerra $^{3}$, Eduardo Pérez-Tijerina $^{1}$, Abel Fundora ${ }^{4}$ \\ ${ }^{1}$ Faculty of Physical-Mathematical Sciences, Universidad Autónoma de Nuevo León, San Nicolas de los Garza, \\ Nuevo León 66451, México. \\ ${ }^{2}$ Hybrid Materials Laboratory (HML), Department of Materials, Engineering (DIMAT), Faculty of Engineering, \\ University of Concepcion, 270 Edmundo Larenas, Casilla 160-C, 4070409 Concepcion, Chile. \\ ${ }^{3}$ Advanced Materials Research Center S.C., Unidad Monterrey-PIIT, Apodaca, Nuevo León 66600, México. \\ ${ }^{4}$ Institute of Materials Science and Technology (IMRE), Universidad de La Habana, Zapata y G, Vedado, CP 10400 \\ La Habana, Cuba.
}

Corresponding author: francisco.solispm@uanl.edu.mx

\begin{abstract}
Vertically arrayed $\mathrm{ZnO}$ nanorods were synthesized by a hydrothermal method on homoseed layers deposited using atomic layer deposition (ALD) and heat-treated at various temperatures ranging from 200 to $600{ }^{\circ} \mathrm{C}$ in air. The effect of the annealing temperatures on nanorod formation was investigated. With increasing temperature, the microstructure of the $\mathrm{ZnO}$ seed layers changed from nanocrystals to coarse polycrystals with a preferred orientation, which led to an increase in the length and diameter of the solvothermally grown nanorods. The effects of the post-heated $\mathrm{ZnO}$ seed layers on the structural and optical properties of the $\mathrm{ZnO}$ nanostructures were investigated by scanning electron microscopy (SEM), x-ray diffraction (XRD) spectroscopy and UV-Vis spectroscopy. The average grain sizes in the $\mathrm{ZnO}$ seed layers increased with increasing post-heating temperature. The $\mathrm{ZnO}$ seed layers post-heated in the range $200-600{ }^{\circ} \mathrm{C}$ affected the residual stress, lattice distortion in the $\mathrm{ZnO}$ nanostructures and the intensity, positions, and full widths at half maximum of $2 \theta$ in the XRD for the $\mathrm{ZnO}$ nanostructures. In this work, it is demonstrated that the heat-treatment temperature of $\mathrm{ZnO}$ seed layer plays an important role in the crystallinity and alignment of the $\mathrm{ZnO}$ nanorods.
\end{abstract}

\section{Introducción}

The study of materials in one dimension (1D) has become a competitive advantage in the field of nanoscience and nanotechnology. 1D $\mathrm{ZnO}$ nanostructures such as nanotubes [1,2], nanorods [3], nanobelts [4] and nanowires [5] and nanonails [5] stimulate interest in scientific research because of their importance in fundamental physics studies and its applications in nanoelectronics, nanomechanics and flat panel display devices.

Particularly, the application of devices $\mathrm{ZnO}$ nanostructures based optoelectronic dimensional (1D) have become a priority area of scientific and technological interest [6-8]. Novel applications of vertically arrayed $\mathrm{ZnO}$ nanorods include piezonanogenerators, UV lasers, gas sensors cells and photocatalysis [9]. 
For applications of nanostructured materials, usually it required that the crystalline morphology, orientation and surface architecture nanostructure can be controlled during the preparation process. There different methods for synthesis of $\mathrm{ZnO}$ nanostructures, such as Vapor Phase Transport (VPT) [10-12], Pulsed Laser Deposition (PLD,) [13], Chemical Vapor Deposition (CVD,) [14, 15], Electrochemical Deposition [16] and arc discharge [16], which have been widely used for prepare $\mathrm{ZnO}$ nanostructures. These aforementioned techniques are very complex processes, sophisticated equipment and high temperatures which make it very difficult for large scale manufacturing of these nanostructures to commercial applications. Contrary to these techniques, chemical aqueous methods show great advantages because of its easy operation and low temperature $\left(95^{\circ} \mathrm{C}\right)[17,18]$, which makes it very low cost. However, the $\mathrm{ZnO}$ nanostructures grown by these chemical methods show low reproducibility, difficulty in controlling the size, however, it still remains a major challenge control the growth of $\mathrm{ZnO}$ nanostructures.

In applications for $\mathrm{ZnO}$ nanostructures, it is required that not only its crystal morphology, and surface orientation are controlled during preparation process, but the quality will also improve their optical and electronic properties. Unfortunately, $\mathrm{ZnO}$ nanostructures grow relatively at low temperature $\left(<100{ }^{\circ} \mathrm{C}\right)$ show a poor crystallization and not good optical properties.

To grow $\mathrm{ZnO}$ nanorods, various synthesis methods have been utilized, such as vapor-liquid-solid (VLS) growth $[19,20]$ chemical vapor deposition [21] and electrochemical deposition [22, 23]. However, those methods require severe conditions or a catalyst for nanorod growth.

The hydrothermal solution method has many merits that can make $\mathrm{ZnO}$ nanorods grow at low temperatures at low cost. To fabricate $\mathrm{ZnO}$ nanorods in liquid solution, the effects of zinc salt, concentration of zinc salt, $\mathrm{pH}$, growth temperature, and growth time affect growth rate, morphology and aspect ratio. By decreasing the growth temperature from 90 to $60{ }^{\circ} \mathrm{C}$, the average diameter of the $\mathrm{ZnO}$ nanorods decreases [24]. By increasing the concentration of the zinc source, the length and diameter of the $\mathrm{ZnO}$ nanorods increase [25]. By controlling the $\mathrm{pH}$ of the aqueous solution, the $\mathrm{ZnO}$ nanostructure morphologies and growth rate can be changed [26]. The length and diameter of the $\mathrm{ZnO}$ nanorods are affected by the growing time [27].

In addition, the seed material is also important for the growth of high-quality $\mathrm{ZnO}$ nanorods [28]. Nevertheless, until now, it is not well understood the seed layer role on the growth mechanism for $\mathrm{ZnO}$ nanorods. Some reports state that by forming layers of textured $\mathrm{ZnO}$ films by ALD on a substrate, a seeded surface can be used to fabricate high density vertical nanorod arrays [29, 30]. From the results, it is observed that thickness influences the texture of ALD $\mathrm{ZnO}$ layer and thus, the crystallographic nature of the seed layer that determines the ulterior nanorod growth type.

In this study, homo-ZnO thin films prepared by an ALD process were used as a seed layer to grow vertically aligned nanorods. The degree of crystallization in the seed layers was changed using different annealing temperatures after formation of the seed layers. Complementary to all available papers, this work is focused exclusively on the thermal treatment effect of ALD $\mathrm{ZnO}$ seed layer to improve crystal quality of vertical $\mathrm{ZnO}$ nanorod arrays. We study the dimensional, morphological, orientation and optical properties of the $\mathrm{ZnO}$ nanorods using a hybrid growth method that consists in three steps: i) a textured seed layer obtained by ALD, ii) a thermal treatment for ALD $\mathrm{ZnO}$ seed layer and iii) vertical $\mathrm{ZnO}$ nanorods growth by hydrothermal method. The reported contributions have considered only two steps $[29,30]$.

\section{Experimental section}

The fabrication procedure for the growth of the nanorods consisted of three steps: preparation of a seed-textured $\mathrm{ZnO}$ thin layer by ALD, thermal treatment in oxygen atmosphere of seed layer and the nanorod array growth by hydrothermal.

\subsection{Synthesis of $\mathrm{ZnO}$ films by ALD}

$\mathrm{ZnO}$ films with a thickness of $80 \mathrm{~nm}$ were deposited on glass substrates by ALD using a Savannah 100 ALD system from Cambridge Nanotech. Diethylzinc (DEZn) was used as the precursor for zinc and deionized water was used as the oxidation source. The growth cycle consists of precursor exposures and $\mathrm{N}_{2}(99.9999 \%)$ purge following the sequence of $\mathrm{DEZn} / \mathrm{N}_{2} / \mathrm{H}_{2} \mathrm{O} / \mathrm{N}_{2}$ with 
corresponding duration of $0.1 \mathrm{~s} / 5 \mathrm{~s} / 0.1 \mathrm{~s} / 5 \mathrm{~s}$. After each $\mathrm{N}_{2}$ purging, the reactor was pumped down to 0.1 Torr. DEZn and $\mathrm{H}_{2} \mathrm{O}$ were fed into the chamber through separate inlet lines and nozzles. In the ALD method reagents (precursors) are introduced sequentially into the growth chamber and when precursors reach the substrate are interspersed by cycles of purging with inert gas $\left(\mathrm{N}_{2}\right)$. The opening and closing sequences of the valves were controlled by a computer. Precursor introduction was done by opening the inlet valve between the reservoir and reactor chamber while the outlet valve was closed. The pressures of the DEZn and $\mathrm{H}_{2} \mathrm{O}$ in the reactor chamber were approximately 1 and 2 torr, respectively, monitored by a vacuum gauge. The substrate temperature was maintained at $177{ }^{\circ} \mathrm{C}$ during the deposition. The reaction was repeated 800 cycles to obtain the $\mathrm{ZnO}$ films with a thickness of $80 \mathrm{~nm}$.

\subsection{Thermal treatment of seed layer under oxygen atmosphere}

The ALD $\mathrm{ZnO}$ seed layer films were annealed at various temperatures ranging from 200 to $600{ }^{\circ} \mathrm{C}$ for $1 \mathrm{~h}$ under oxygen to induce crystallization. The thickness of the $\mathrm{ZnO}$ seed layers was approximately $80 \mathrm{~nm}$.

\subsection{Growth of $\mathrm{ZnO}$ nanorods through hydrothermal process}

In this process, $\mathrm{Zn}\left(\mathrm{NO}_{3}\right)_{2} \quad(\mathrm{ZNT})$ and hexamethylenetetramine (HMT) purchased from Sigma-Aldrich (St Louis, MO) were used as reagents. The $\mathrm{ZnO}$ nanorods were grown in aqueous solutions of zinc nitrate $\left(\mathrm{Zn}\left(\mathrm{NO}_{3}\right)_{2} \cdot 6 \mathrm{H}_{2} \mathrm{O}\right)$ $0.05 \mathrm{M}$ and hexamine $\left.\left(\mathrm{CH}_{2}\right)_{6} \mathrm{~N}_{4}\right) \quad 0.05 \mathrm{M}$ in deionized water; the ZNT:HMT molar ratio was always $\{1: 1\}$. The thermal treated ALD-ZnO seed layer were placed in face up position into glass reactor with screw cap and then equal amounts of both ZNT and HMT solutions were added. The reactor was immersed in a water bath at $90{ }^{\circ} \mathrm{C}$ with mild agitation during 4 hours. Finally, the samples were rinsed with deionized water for several times and dried at $90{ }^{\circ} \mathrm{C}$ for several hours before characterization. The samples were structurally and morphologically characterized by X-ray diffraction (XRD) using a Philips X'Pert PW3040 diffractometer with $\mathrm{Cu}-\mathrm{K} \alpha$ radiation and field- emission scanning electron microscopy in a Hitachi S-5500 Field Emission Gun (FEG) ultra high-resolution scanning electron microscope (SEM) $(0.4 \mathrm{~nm}$ at $30 \mathrm{kV})$ with a BF/DF DuoSTEM detector. Additionally, the composition was determined by energy dispersive X-ray spectroscopy (EDS, Inca Oxford, attached to the FE-SEM) and the seed-textured $\mathrm{ZnO}$ layer surface was analyzed by atomic force microscopy (AFM).

\section{Results and discussion}

\subsection{ZnO seed layer}

SEM was used to examine the morphology of the thermal treated $\mathrm{ZnO}$ seed layers. Figure 1 shows the morphology of the $\mathrm{ZnO}$ seed layer $(80 \mathrm{~nm})$ obtained by ALD with the experimental conditions mentioned above with and without thermal treatment at $200{ }^{\circ} \mathrm{C}, 300{ }^{\circ} \mathrm{C}, 400{ }^{\circ} \mathrm{C}, 500{ }^{\circ} \mathrm{C}$ and $600{ }^{\circ} \mathrm{C}$. Figure 1a shows SEM image of the $\mathrm{ZnO}$ seed layers as deposited by ALD.

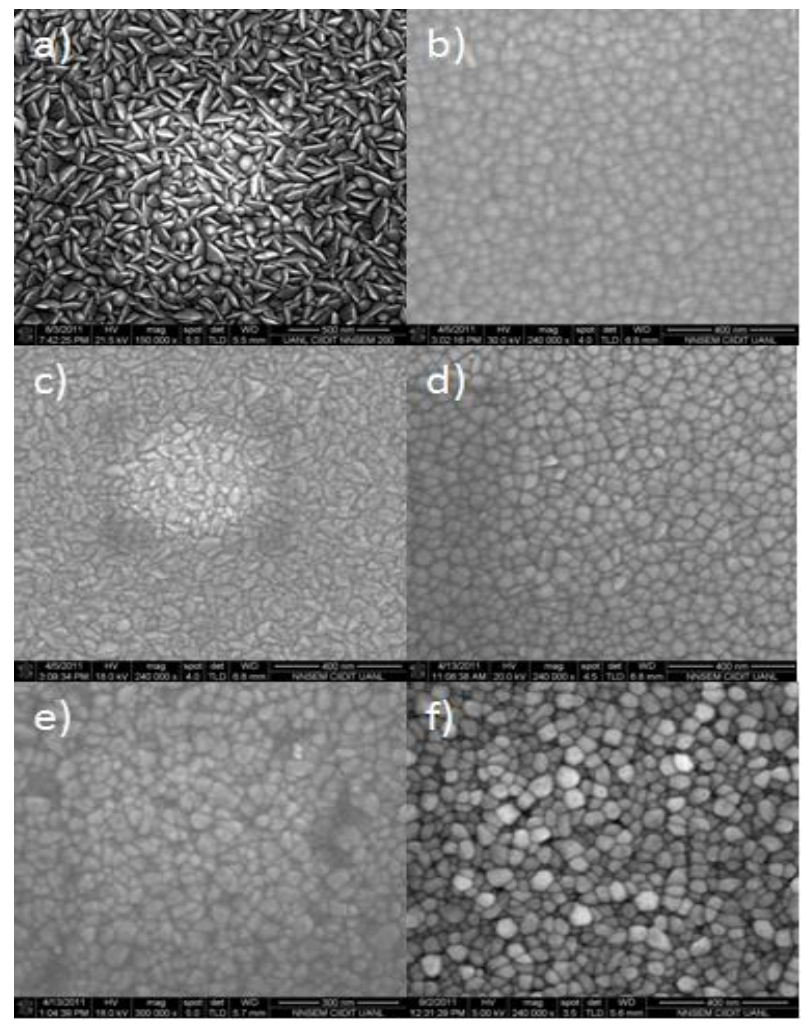

Figure 1. SEM images of the $80 \mathrm{~nm} \mathrm{ZnO}$ seed layer deposited by ALD with and without thermal treatment. a) 80 $\mathrm{nm} \mathrm{ZnO} \mathrm{seed} \mathrm{layer} \mathrm{without} \mathrm{heat} \mathrm{treatment,} \mathrm{b)} \mathrm{-} \mathrm{f)} \mathrm{ZnO}$ seed layer with heat treatment at $200^{\circ} \mathrm{C}, 300^{\circ} \mathrm{C}, 400^{\circ} \mathrm{C}, 500^{\circ} \mathrm{C}$ and $600^{\circ} \mathrm{C}$ respectively. 
The ALD-fabricated $\mathrm{ZnO}$ seed layer without postthermal treatment showed a less dense and inhomogeneous film with grains of different sizes. However, the $\mathrm{ZnO}$ seed crystals were densely grown and the grain size increased gradually with increasing annealing temperature. The average grain size of the seed crystals evaluated from SEM images was increased from $28 \mathrm{~nm}$ at $200{ }^{\circ} \mathrm{C}$ to 65 $\mathrm{nm}$ at $600{ }^{\circ} \mathrm{C}$. The increase in grain size can be understood by an Ostwald ripening mechanism [31]. In particular, Ostwald ripening occurs frequently over a wide range of temperatures when the density of nucleation sites is dispersed randomly. The degree of crystallization is expected to affect the morphology and distribution of the $\mathrm{ZnO}$ nanorods. As shown in Figure. 1a to 1f, the change in annealing temperature of the seed layers impacts the morphology and density of the $\mathrm{ZnO}$ crystals on seed layer. It is observed that the morphology changes from small grains to larger grains forming mosaics. It also increases the crystal volume until obtain a quasi-planar surface on the $\mathrm{ZnO}$ seed layer.

The X-ray diffraction patterns of the $\mathrm{ZnO}$ seed layer with the different heat treatments are shown in Figure 2. The diffraction X-ray pattern of the $\mathrm{ZnO}$ seed layer of is observed without and their respective heat treatments can be observed the single-phase and textured character of the $\mathrm{ZnO}$ ultrathin $(80 \mathrm{~nm})$ layer obtained by the ALD technique. The diffraction Peaks correspond to a single phase, with hexagonal Wurtzite structure type (ICSD 31052, PDF 36-1451), described by the reflections of the crystallographic planes (100), (110) and (002), the latter being the most intense. The diffraction pattern reveals a preferential growth along the direction [002]. With the heat treatment promoted the crystallization and the growth of the grain size in the ultrathin $\mathrm{ZnO}$ layer. The peak intensity in the (002) increases with increasing the heat treatment temperature which favors the atomic diffusion, crystallization processes, crystallographic order and increasing the grain size which was observed by SEM. The formation and faceting of the hexagonal phase observed are indicative of the preferential orientation in the plane (002).

Figure 3 shows the transmittance spectrum curves of $\mathrm{ZnO}$ layer with and without heat treatments. It is observed that the transmittance increases in the visible region while decreases in the UV region with increasing the treatment temperature. The increase of the transmittance in the visible region may be due to a surface effect by increasing the temperature, which forms a flat surface preventing the dispersion of light, unlike the ultrathin $\mathrm{ZnO}$ film obtained by ALD which is entirely rough. Similarly, the heat treatment improves the $\mathrm{ZnO}$ transmittance due to the reaction with the oxygen.

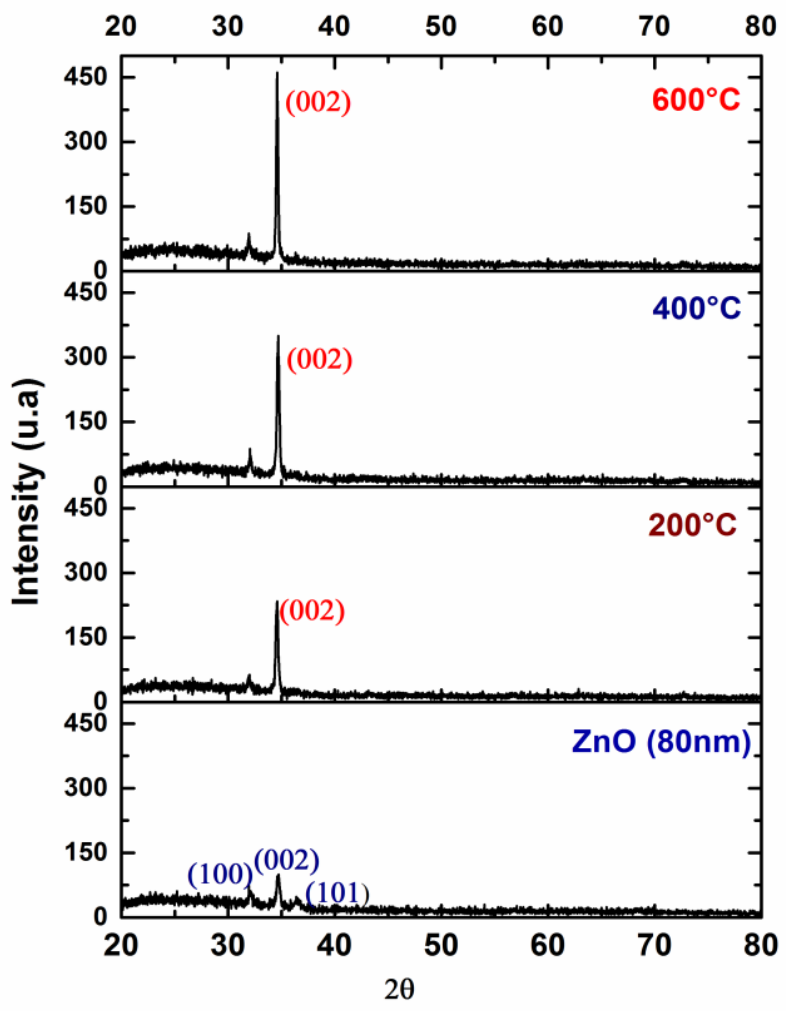

Figure 2. The X-ray diffraction patterns of the $\mathrm{ZnO}$ seed layer with the different heat treatments.

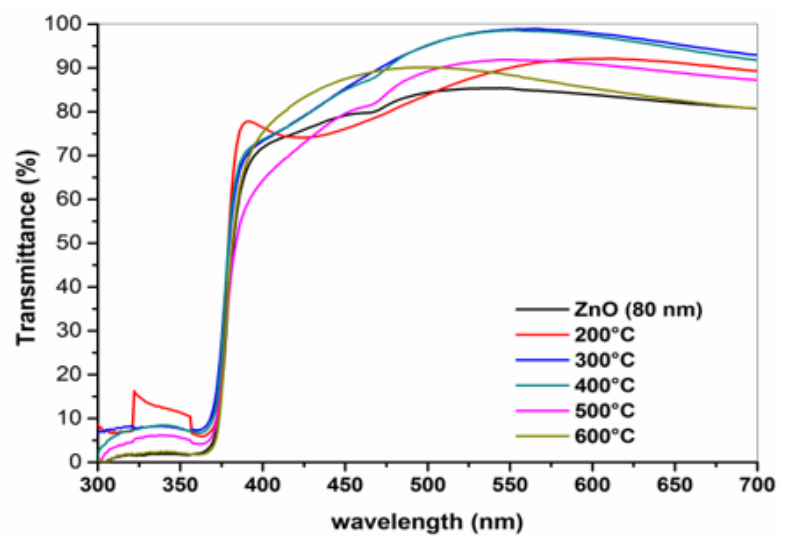

Figure 3. Transmittance spectrum curves of $\mathrm{ZnO}$ seed layer with and without heat treatments. 

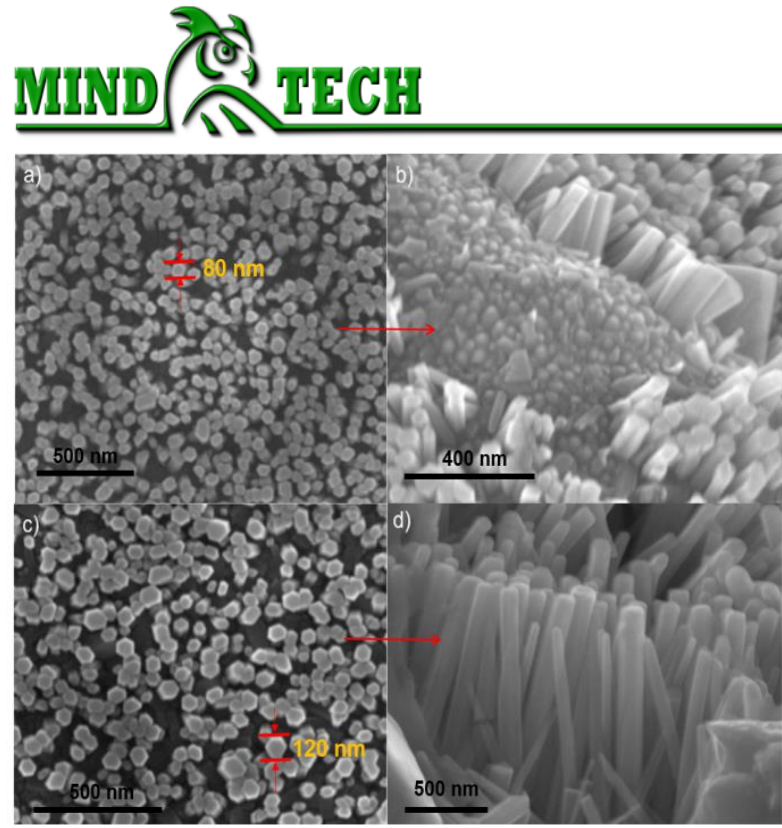

Figure 4. SEM images of the $\mathrm{ZnO}$ nanorods grown on thermal treated seed layer, a) and b) Top and lateral view of the $\mathrm{ZnO}$ nanorods growth on $\mathrm{ZnO}$ seed layer annealed at $300{ }^{\circ} \mathrm{C}, \mathrm{c}$ ) and d) Top and lateral view of the $\mathrm{ZnO}$ nanorods growth on $\mathrm{ZnO}$ seed layer annealed at $600{ }^{\circ} \mathrm{C}$.

The change in the absorption edge can be attributed to the quality of the $\mathrm{ZnO}$ ultrathin film with the increase of heat treatment temperature. When temperature increases, the number of defects decreases improving the quality of the $\mathrm{ZnO}$ film. This means that the electronic structure of $\mathrm{ZnO}$ changes whit temperature rise, making it a more perfect structure. These results can be validated by the previously obtained SEM images and the diffraction patterns, showing the changes of the $\mathrm{ZnO}$ seed layer with the increase of the heat treatment temperature to get a planar and textured surface.

\section{2 $\mathrm{ZnO}$ nanorods grown on thermal treated seed layer}

In the second stage, the $\mathrm{ZnO}$ nanorods were synthesized under the same conditions by a hydrothermal method on these seed crystals. As shown in Figure 4 the change in annealing temperature of the seed layers impacts in the morphology and density of the $\mathrm{ZnO}$ nanorods. The most striking difference in the SEM images is that the average length of the nanorods increases with increasing annealing temperature of the seed layers where the average length of the nanorods increased from $450 \mathrm{~nm}$ at $300{ }^{\circ} \mathrm{C}$ to $1200 \mathrm{~nm}$ at $600{ }^{\circ} \mathrm{C}$. The diameter of the nanorods also increased slightly.
For example, the samples thermally annealed at 300 and $600{ }^{\circ} \mathrm{C}$ had diameters of 80 and $120 \mathrm{~nm}$, respectively. All the $\mathrm{ZnO}$ nanorods were generally grown along the c-direction with polar axis. It is also expected that thermal treatment promotes the enhancement in the degree of the c-axis-preferred orientation of the seed layers. Therefore, the increase in the annealing temperature may induce the rapid growth along the c-axis. From the planview SEM images in Figure 4a and 4c, the number of nanorods per-unit area was approxi-mately 55 and 34 per $1 \mu \mathrm{m} \times 1 \mu \mathrm{m}$ for the samples annealed at 300 and $600{ }^{\circ} \mathrm{C}$, which are proportional to the density of the seed crystals.

As observed by SEM, the diameter of the nanorods increased with increasing annealing temperature, i.e. an enlarged grain size in the seed crystals results in an increase in the diameter and length of the nanorods produced subsequently, as shown in Figure. 4. Consequently, the increase in the grain size by thermal annealing is expected to promote the reaction rate along the vertical and lateral directions simultaneously, and the resulting volume of nanorods increases significantly. Even though there is a slight inclination of the nanorods, all vertically arrayed nanorods fabricated by the hydrothermal method have a hexagonal surface shape and a preferential orientation along the caxis, regardless of the annealing temperature. On the basis of the SEM, the crystallization of seed layers by post-thermal annealing promotes the formation of vertically arrayed nanorods, and also augments the width of the nanorods by coarsening the grains in the seed layers.

$\theta-2 \theta$ scan XRD was performed to compare the crystallinity of the $\mathrm{ZnO}$ seed layers and $\mathrm{ZnO}$ nanorods. As shown in Figure. 5 faint (002) diffraction peaks were observed for the samples annealed at high temperatures due to crystallization of the seed layers. The diffraction peaks from the $\mathrm{ZnO}$ nanorods in Figure 5 were also intensified when the annealing temperature was increased. Annealing at high temperatures induces a shift in the (002) $\mathrm{ZnO}$ peak for the nanorods to a lower angle. This suggests an increase in the c lattice constant from $0.5188 \mathrm{~nm}\left(200{ }^{\circ} \mathrm{C}\right)$ to $0.5198 \mathrm{~nm}$ $\left(600{ }^{\circ} \mathrm{C}\right)$. In particular, the value estimated from the sample annealed at $600{ }^{\circ} \mathrm{C}$ was closer to the clattice parameter $(0.5207 \mathrm{~nm})$ of bulk $\mathrm{ZnO}$, indicating reduced stress. The above means that longer and thicker nanorods with large dimensions 


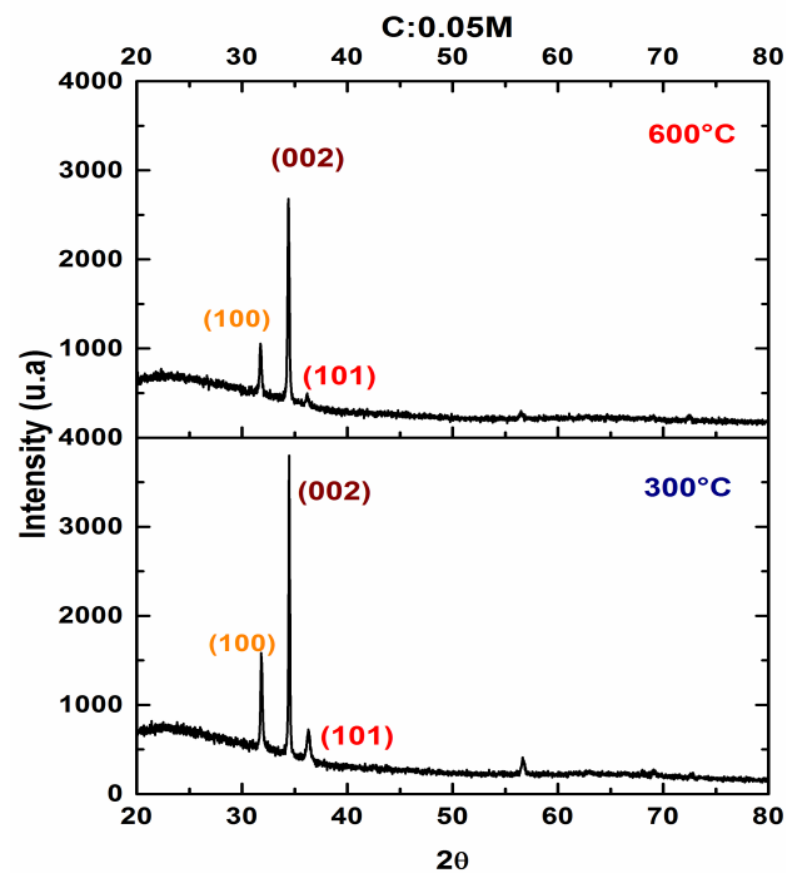

Figure 5. The X-ray diffraction patterns of the $\mathrm{ZnO}$ nanorods growth on the annealed $\mathrm{ZnO}$ seed layer.

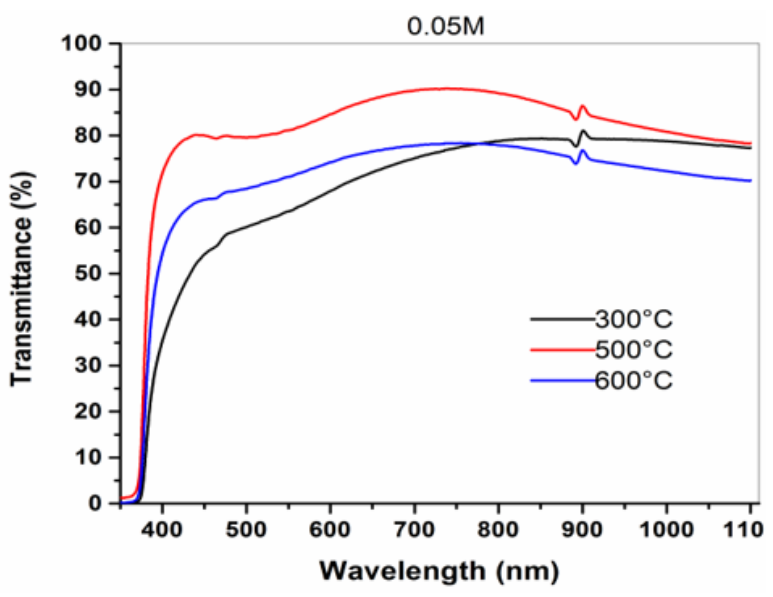

Figure 6. Transmittance spectrum curves of the $\mathrm{ZnO}$ nanorods at different temperatures of seed layer heat treatment.

assisted by the crystallized seed layers induce lattice constant corresponding to the near bulk.

The patterns for all nanostructures exhibit intense (002) diffraction peaks, indicating that the preferred growth orientation of nanorods is along (002) direction because their vertical growth rate is rapid and because their lateral growth is relatively limited. Figure $5 \mathrm{~b}$ shows the full width at half maximum (FWHM) and the position of the peaks in the XRD patterns for the $\mathrm{ZnO}$ nanorods grown on $\mathrm{ZnO}-\mathrm{ALD}$ seed layers post-heated at various temperatures. The FWHM of the (002) diffraction peak for $\mathrm{ZnO}$ is reported to be closely related to both grain size and crystal quality. The FWHM is inversely proportional to grain size. Hence narrower FWHM and larger grain sizes imply better crystal quality. The position of the (002) peak in the XD spectra shifted with changing $\mathrm{ZnO}$ seed layers post-heating temperature, indicating that $\mathrm{ZnO}$ seed layers post-heating temperature affected the structural properties of the $\mathrm{ZnO}$ nanorods. The shift in the position of the (002) peak as a function of the $\mathrm{ZnO}$ seed layer postheating temperatures implies a change in the amount of residual stress $(\sigma)$ compared to that in strain-free $\mathrm{ZnO}$. The residual stress $\sigma$ is generated in the $\mathrm{ZnO}$ nanorods because of the differences in the lattice constant and the thermal expansion coefficient between the rods and the seed layer.

\subsection{Effect of thermal treatment of ALD $\mathrm{ZnO}$ seed layer on the growth of $\mathrm{ZnO}$ nanorods}

The results from SEM images suggest that the growth rate of the $\mathrm{ZnO}$ nanorods during hydrothermal synthesis is strongly dependent on the annealing temperature of the seed layer. In our study, the density of $\mathrm{ZnO}$ nanorods on the seed layer annealed at $600{ }^{\circ} \mathrm{C}$ was found to be $2 \times 10^{10}$ $\mathrm{cm}^{-2}$. In contrast the nanorods grown at lower temperatures exhibited comparable densities but lower if compared to those grown an ALD seed later without thermal treatment.

The nanorods grown on seed layers annealed at $600{ }^{\circ} \mathrm{C}$ exhibited larger average diameters when compared with diameters of seed layer before nanorods growth. Thus, the lower density of nanorods might be caused by the nanorods larger diameter. The lateral growth is not as effectively suppressed, resulting in larger-diameters rods. The influence of the seed layer is mainly showed in perfect and well faceted basal planes for all thermal treated substrates. The differences in the $\mathrm{ZnO}$ nanorod growth on different seed layers are explained by the competition between neighboring nanorods in addition to the preferential growth axis of the crystal.

Figure 6 shows the transmittance curves of $\mathrm{ZnO}$ nanorods at different temperatures of treatment on the seed, it is noted a decreasing of the transmitttance visible region of the $\mathrm{ZnO}$ nanorods whit 
increasing heat treatment temperature. This may be because that at higher temperatures are much larger diameters that if are not grown at the same height can be a loss by light scattering resulting in a decrease in the transmittance.

\section{Conclusions}

Vertically arrayed $\mathrm{ZnO}$ nanorods were suesfully synthesized by a hydrothermal method on homoseed layers deposited using ALD and heat-treated at various temperatures ranging from 200 to 600 ${ }^{\circ} \mathrm{C}$ in air. The average grain size of the seed crystals increased gradually with increasing annealing temperature.

The heat treatment promoted the crystallization and the growth of the grain size in the ultrathin $\mathrm{ZnO}$ layer. The peak intensity in the (002) increases with increasing the heat treatment temperature which favors the atomic diffusion, the crystallization processes into the preferential orientation in the plane (002). The change in annealing temperature of the seed layers impacts in the morphology and density of the $\mathrm{ZnO}$ nanorods. The average length of the nanorods increased from $450 \mathrm{~nm}$ at $300{ }^{\circ} \mathrm{C}$ to $1200 \mathrm{~nm}$ at $600{ }^{\circ} \mathrm{C}$ and diameters from 80 and $120 \mathrm{~nm}$, respectively.

The number of nanorods per-unit area was approximately 55 and 34 per $1 \mu \mathrm{m} \times 1 \mu \mathrm{m}$ for the samples annealed at 300 and $600{ }^{\circ} \mathrm{C}$, which are proportional to the density of the seed crystals. The heat treatment affected the residual stress, lattice distortion in the $\mathrm{ZnO}$ nanostructures and the intensity, positions, and full widths at half maximum of $2 \theta$ in the XRD for the $\mathrm{ZnO}$ nanorods.

\section{Acknowledgements}

The authors JLV would like to thank the Nanoscience and Nanotechnology Group $\left(\mathrm{GN}^{2}\right)$ belonging to Faculty of Mathematics and Physical Sciences (FCFM) of the UANL. For the support and contribution of this research. Also the authors are grateful to electronic microscopy laboratory of the CIIDIT-UANL. MFM to The Advanced Nanocomposites Research Group (GINA) at the Materials Engineering Department (DIMAT), University of Concepción, Concepción Chile.

\section{Conflict of interests}

Authors declare that there are no conflicts of interest associated with the information contained in this work.

\section{References}

[1]. S. Iijima, Nature 354 (1991) 56.

[2]. M. H. Huang, S. Mao, H. Feick, H. G. Yan, Y.Y. Wu, H. Kind, E. Weber, R. Russo, P. D. Yang, Science 292 (2001) 1897.

[3]. J. Y. Li, X. L. Chen, H. Li, M. He, Z. Y. Qiao, J. Crys.Growth 233 (2001) 5.

[4]. Z. W. Pan, Z. R. Dai, Z. L. Wang, Science 291 (2001) 1947.

[5]. F Solis-Pomar, A Jaramillo, J Lopez-Villareal, C Medina, D Rojas. Ceramics International, 42 (2016) 18045.

[6]. M.J. Zheng, L.D. Zhang, G.H. Li and W. Z. Shen, Chem. Phys. Lett. 363 (2002) 123.

[7]. C. H. Liu, J. A. Zapien, Y. Yao, X. M. Meng, C. S. Lee, S. S. Fan, Y. Lifshitz and S. T. Lee, Adv.Mater. 15 (2003) 838.

[8]. P. X. Gao and Z. L. Wang, J. Phys. Chem. B, 108 (2004) 7534.

[9]. T. H. Fang, S. H. Kang, J. Phys. D: Appl. Phys. (2008) 41, 245303.

[10]. J. S. Lee, K. Park, M. I. Kang, I. W. Park, S. W. Kim, W. K. Chom, H. S. Han and S. Kim, J. Cryst. Growth 254 (2003) 423.

[11]. Q. X. Zhao, P. Klason and M. Willander, Appl. Phys.A, 88 (2007) 27.

[12]. M. H. Huang, Y. Wu, H. Feick, N. Tran, E. Weber and P. Yang, Adv. Mater. 13(2001) 113-116.

[13]. Y. Sun, G. M. Fuge and M. N. R. Ashfold, Chem. Phys. Lett. 396 (2004) 21.

[14]. J. Wu and S. C. Liu, Adv. Mater. 14 (2002) 215.

[15]. W. I. Park, D. H. Kim, S.W. Jung and G. C. Yi, Appl. Phys. Lett. 80 (2002) 4232.

[16]. H. D. Yu, Z. P. Zhang, M. Y. Han, X. T. Hao and F. R. Zhu, J. Am. Chem. Soc. 127 (2005) 2378.

[17]. L. Vayssieres, K. Keis, S. E. Lindquist and A. Hagfeldt J. Phys. Chem. B 105 (2001) 3350.

[18]. L. Vayssieres, Adv. Mater. 15 (2003) 464.

[19]. Chik, H.; Liang, J.; Cloutier, S. G.; Kouklin, N.; Xu, J. M. Appl.Phys. Lett. 84 (2004) 3376.

[20]. Huang, M. H.; Mao, S.; Feick, H.; Yan, H.; Wu, Y.; Kind, H.; Weber, E.; Russo, R.; Yang, P. Science 292 (2001) 1897.

[21]. Wu, J.-J.; Liu, S.-C. AdV. Mater., 14 (2002) 215.

[22]. Cui, J.; Gibson, U. J. J. Phys. Chem. B 109 (2005) 22074.

[23]. Liu, R.; Vertegel, A. A.; Bohannan, E. W.; Sorenson, T. A. Chem. Mater. 13 (2001) 508.

[24]. Guo, M.; Diao, P.; Wang, X.; Cai, S. J. Solid State Chem. 178 (2005) 3120.

[25]. Hirano, S.; Takeuchi, N.; Shimada, S.; Masuya, K.; Ibe, K.; Ysunakawa, H.; Kuwabara, M. J. Appl. Phys. 98 (2005) 094305/1-09430.5/7.

[26]. Pal, U. Santiago, P. J. Phys. Chem. B, 109 (2005) 15317. 
[27]. Tak, Y.; Yong, K. J. Phys. Chem. B 109 (2005) 19263.

[28]. Cui, J. B.; Daghlian, C. P.; Gibson, U. J.; Pusche, R.; Geithner, P.; Ley, L. J. Appl. Phys. 97 (2005) 044315/1-04431.5/7.

[29]. F. Solís-Pomar, E. Martínez-Guerra, M.F. Meléndrez, E. Pérez-Tijerina, Nanoscale Res. Lett. 6 (2011) 524.
[30]. M.F. Meléndrez, L. Deepak, E. Pérez-Tijerina, E. Martínez and M. Jose-Yacaman, J. Mat. Sci. 47 (2012) 2025.

[31]. M. Epifani, J. Arbiol, E. Pellicer, J. R. Morante, Chem. Mater. 19 (2007) 4919. 